\title{
Erratum to: Hypertrophic Cardiomyopathy: Preclinical and Early Phenotype
}

\author{
Carolyn Y. Ho
}

Published online: 19 June 2013

(C) Springer Science+Business Media New York 2013

Erratum to: Journal of Cardiovascular Translational Research

DOI 10.1007/s12265-009-9124-7

Figure 7 in this article was adapted from the website http:// folk.ntnu.no/stoylen/strainrate/ of Professor Asbjørn Støylen and the Norwegian University of Science and Technology.

The online version of the original article can be found at http:// dx.doi.org/10.1007/s12265-009-9124-7.

C. Y. Ho $(\bowtie)$

Cardiovascular Division, Brigham and Women's Hospital,

75 Francis Street, Boston, MA 02115, USA

e-mail: cho@partners.org 